\title{
A MÚSICA COMO FERRAMENTA PEDAGÓGICA NA EDUCAÇÃO INFANTIL
}

\author{
Dulcenéia de Moraes Santos ${ }^{1}$ \\ Ilza Francisca da Silva ${ }^{2}$ \\ Isabel Cristina da Silva ${ }^{3}$ \\ Josedelma Martins Pinheiro da Silva Costa ${ }^{4}$ \\ Miriã Dias Ferreira ${ }^{5}$
}

RESUMO: A música é uma linguagem universal que existe em todas as culturas e no quotidiano das pessoas, ajuda a desenvolver o raciocínio lógico, dá implicações emocionais, como ferramenta de comunicação social, será uma ferramenta essencial para ser utilizada no processo educativo, bem como uma maneira divertida de descobrir novos aprendizados. Portanto, este artigo tem como objetivo fornecer informações sobre o uso da música na educação infantil. Especificamente, discuta sua contribuição como recurso educacional. Pode promover uma educação de qualidade e uma prática educacional eficaz e contribuir para a educação integrada das crianças. Também tente refletir a real intenção de usar a música no espaço escolar. O tema deste artigo é derivado de observações e experiências de estágios na área de educação infantil. Este artigo é dirigido a muitos educadores e ajuda a refletir práticas educacionais que usam a música na educação infantil para proporcionar às crianças uma aprendizagem lúdica, lúdica e criativa.

Palavras-chave: Educação Infantil. Música. Desenvolvimento. Criança.

ABSTRACT: Music is a universal language that exists in all cultures and in people's daily lives, helps to develop logical reasoning, gives emotional implications, as a social communication tool, it will be an essential tool to be used in the educational process, as well as a fun way to discover new learnings. Therefore, this article aims to provide information about the use of music in early childhood education. Specifically, discuss your contribution as an educational resource. It can promote quality education and effective educational practice and contribute to the integrated education of children. Also try to reflect the real intention of using music in the school space. The theme of this article is derived from observations and experiences of internships in the area of early childhood education. This

\footnotetext{
I Graduada em Pedagogia para a Educação Infantil pela UFMT - Universidade Federal de Mato Grosso, Especialista em Docência na Educação Infantil pela UFMT - Universidade Federal de Mato Grosso.

${ }^{2}$ Graduada em Pedagogia pela UNOPAR - Universidade Norte do Paraná, Especialista em Docência na Educação Infantil pela UFMT - Universidade Federal de Mato Grosso.

3 Graduada em Pedagogia pela UNOPAR - Universidade Norte do Paraná, Especialista e Educação Infantil pela FACIB - Faculdade Impactos Brasil.

${ }_{4}$ Graduada em Pedagogia pela Faculdade Afirmativo, Especialista em Educação Infantil pelo IESMIG Instituto de Ensino Superior de Minas Gerais.

5 Graduada em Pedagogia pela Faculdade Invest. de Ciências e Tecnologia, Especialista em Educação Especial AEE pela Faculdade Invest. de Ciências e Tecnologia.
} 
article is aimed at many educators and helps to reflect educational practices that use music in early childhood education to provide children with playful, playful and creative learning.

Keywords: Early Childhood Education. Song. Development. Kid.

\section{INTRODUÇÃO}

A música existe na vida humana desde o início, abrangendo a história humana como uma variedade de formas de expressão cultural e emocional. Hoje a música existe não apenas em grupos musicais e expressões culturais, mas também em muitas atividades humanas, como as artes que contribuem para o desenvolvimento das crianças desde o nascimento até a primeira infância. Ou seja, atividades lúdicas e educativas podem contribuir para o desenvolvimento da criança.

Este artigo tem como objetivo considerar a importância do uso da música em jardins de infância, especialmente a contribuição da música como um recurso educacional para promover a educação holística em crianças em combinação com a prática, possibilita educação de qualidade na Educação Infantil. O problema surgiu a partir de um arranjo de educação infantil supervisionado em que os professores usavam a música de forma não textual e experimentavam o tempo para reproduzir apenas gestos, sem amarrar a música ao momento em que viviam. Produz o ato de cantar. Mecanicamente. Este movimento só é útil para reproduzir a música. Isso se afasta do verdadeiro objetivo de conhecimento e musicalização no dia a dia de uma criança.

O uso da música na Educação Infantil hoje tem finalidades como hora do lanche, hora de dormir e aniversários, mas muitas vezes é usada repetidamente apenas para criar hábitos e atitudes. Nessa visão, sem direcionamento, sem pensar no que está fazendo, a simples mecanização do momento elimina a possibilidade de usar a música para sugerir socialização, desenvolvimento e aprendizagem. Nesse contexto, o objetivo deste estudo foi garantir que a música contribua para o desenvolvimento da criança, complementando uma melhor compreensão e desenvolvimento das atividades que ocorrem na educação infantil., ao invés de uma prática separada, desenvolve as habilidades musicais e outras habilidades da criança, e habilidades. 
Este artigo, foi, organizado na tentativa de demonstrar o potencial da música como ferramenta de ensino. Para tanto, discutiremos primeiramente a educação infantil e suas peculiaridades, em seguida, apresentaremos o tema da educação infantil na segunda etapa. Eles, crianças, professores e práticas educativas, detalham suas características no espaço escolar. O terceiro momento destaca a relação entre a música e as crianças e mostra as diferentes maneiras como a música existe no dia a dia das crianças e em todas as fases de suas vidas. Em seguida, nos momentos, e, mostramos como os professores podem lidar com a música nas aulas de educação infantil e como ela pode ser utilizada como prática coeducativa com o desenvolvimento infantil.

\section{DESENVOLVIMENTO 2.r Educação e Educação Infantil}

A educação, o ato ou processo de educação, existe em todas as sociedades. Porque todos precisam estar atentos à formação pessoal, ajudar a amadurecer e transformar nas diferentes etapas da vida social (LIBÂNEO, 1994).

A educação refere-se à existência do ser humano em todos os aspectos da sociedade, economia e política, e é um processo social que molda as pessoas de acordo com seus conceitos e interesses e influencia constantemente seu desenvolvimento. As pessoas os integram em seu ambiente social atual. Portanto, a educação é entendida como o processo pelo qual o ser humano adquire humanidade. Em suma, a educação é um fenômeno cultural, uma crença e valores que se relacionam com a sua cultura e se desenvolvem de acordo com a realidade econômica de cada um.

A educação é concebida como um processo de formação abrangente, na vida familiar, na convivência humana, inclusive de cidadania e o trabalho como princípio educativo que, segundo a Lei de Diretrizes e Bases da Educação Nacional (LDB), Lei 9.394, de 20 de dezembro de 1996, aponta:

Art. Io A educação abrange os processos formativos que se desenvolvem na vida familiar, na convivência humana, no trabalho, nas instituições de ensino e pesquisa, nos movimentos sociais e organizações da sociedade civil e nas manifestações culturais. 
§ Io Esta Lei disciplina a educação escolar, que se desenvolve, predominantemente, por meio do ensino, em instituições próprias.

§ 2을 A educação escolar deverá vincular-se ao mundo do trabalho e à prática social.

Art. $2^{-}$A educação, dever da família e do Estado, inspirada nos princípios de liberdade e nos ideais de solidariedade humana, tem por finalidade o pleno desenvolvimento do educando, seu preparo para o exercício da cidadania e sua qualificação para o trabalho.

A Educação Infantil, ainda segundo a Lei 9.394/1996 (LDB), considera como a "primeira etapa da educação básica" (Art.29), sendo o seu "atendimento gratuito em creches e pré-escolas, crianças de zero e seis anos”. Ou seja, um “dever do estado" (Art.4으, inciso IV).

Por ser esta etapa muito importante, ela ainda está não associada somente ao cuidar, mas também favorece o desenvolvimento infantil e a aquisição de conhecimentos, tendo como finalidade "[...] o desenvolvimento integral da criança até 6 anos de idade nos seus aspectos físicos, psicológicos, intelectual e social [...]” prescrito no art.29 da LDB. Então, compreende-se, então, que esse seja o primeiro espaço de educação coletiva fora do contexto familiar, onde a criança vivencia momentos coletivos, interage e expressa desejos e curiosidades.

De acordo Revisão das Diretrizes Curriculares Nacionais para a Educação Infantil, essa etapa possui uma função sociopolítica e pedagógica, ou seja, que ofereça condições e recursos para que as crianças usufruam de seus direitos, promovendo igualdade de oportunidade, tornando um espaço de convivência, de construção de identidade e construção de saberes.

Nesse estágio inicial, é importante que as escolas adotem um currículo flexível que atenda às necessidades de seus alunos e enfatizem que eles precisam abordar as seguintes áreas do currículo: autodescoberta, autodescoberta, exploração do ambiente natural e social, comunicação e linguagem. As áreas de linguagem incluem linguagem oral, linguagem matemática, linguagem plástica, expressão física e linguagem musical. Este último aspecto é enfatizado em nosso trabalho para discutir sua importância na educação infantil. 
Portanto, o jardim de infância deve ser um espaço confortável e alegre onde as crianças possam brincar, brincar, sonhar, se sentir à vontade e receber o apoio de que necessita para aprofundar seus conhecimentos.

\subsection{A Educação Infantil}

Quando se trata de educação infantil, é fundamental compreender as formas de interação, pois o desenvolvimento se dá em uma rede sensorial que inclui a criança, o professor, o ambiente educacional e o comportamento.

De acordo com Estatuto da Criança e do Adolescente (ECA), a criança é um indivíduo até os doze anos de idade incompletos. Segundo o dicionário Aurélio (2010), criança é definida como menina ou menino no período da infância, ou seja, período esse que faz parte do ciclo da vida de todo ser humano, fase onde se aprende o novo, novas descobertas, é nela que se aprende a andar, falar, onde aprende a se comportar, conforme as regras de uma determinada sociedade, desenvolvendo uma personalidade, ou seja, a sua identidade.

Para as Diretrizes Curriculares para a Educação Infantil, a criança é: Sujeito histórico e de direitos que, nas interações, relações e práticas que vivencia, constrói sua identidade pessoal e coletiva, brinca, imagina, fantasia, deseja, aprende, observa, experimenta, narra, questiona e constrói sentidos sobre natureza e sociedade produzindo cultura (BRASIL, 20Io, p. 20).

No campo dos educadores, principalmente crianças, os professores nesta fase desempenham muitos papéis e como o papel do professor A é fundamental, eles carregam uma grande responsabilidade, por isso possuem um amplo leque de habilidades, traços e qualidades relacionadas à sua especialidade. Deve ser mostrado. É um agente ativo na educação dos cidadãos, por isso se reflete na escola e na sociedade como um todo.

Para Paige (2010) o papel do educador infantil tem muitas responsabilidades, complicando o papel desse professor, que ele identifica como uma pessoa chave que funciona de forma efetiva e plena quando necessário por meio de muitas funções comuns aos líderes. Frequentemente, eles precisam tomar decisões rápidas sobre a situação, comunicar-se, trabalhar em equipe e interagir uns com os outros como líderes ou como membros de um grupo específico. 
Uma parte importante do trabalho desse professor é tomar decisões sobre suas práticas educacionais. Ou seja, aja de acordo com seu conteúdo e planeje sua implementação. Requer uma visão detalhada e concreta. As ideias são realizadas com base nas atividades diárias e nas necessidades dos alunos.

Segundo Bassedas (1999), a prática educacional deve ser bem planejada e desenvolvida para o crescimento do aluno. Permite que você pense sobre o que pretende alcançar e como será avaliado.

\subsection{A música e a criança}

A educação infantil preocupa-se com a educação inclusiva e inclusiva para crianças com aprendizagem e prática constantes. Este exercício de aprendizagem deve ser divertido, não doloroso. A atividade proposta certamente deve ser pensada para as crianças como uma sugestão interessante para incluir a música no cotidiano dos alunos de uma forma deliberadamente planejada pelo professor.

A existência da música na vida humana é inegável, embora a sua linguagem seja diferente, mas dependendo da origem desta expressão cultural, a música acompanha o desenvolvimento e as relações da música, relações interpessoais de comunidades, bairros e cidades, iluminação espacial e iluminação emocional, a auto-expressão, com as relações afetivas, passa a fazer parte do cotidiano de todos em casa, no trabalho, no celular e no computador, e a música é a expressão de ideias, hábitos, gostos, emoções e comportamento social.

Para o Referencial Curricular para a Educação Infantil a música é a linguagem que se traduz em formas sonoras capazes de expressar e comunicar sensações, sentimentos e pensamentos, por meio da organização e relacionamento expressivo entre som e o silêncio. A música está presente em todas as culturas, nas mais diversas situações: festas, comemorações, rituais, religiosas, manifestações cívicas, políticas etc. (RCNEI, 1998).

De acordo com muitos estudos, as crianças foram expostas à música desde cedo. Isso porque, em muitos estudos, a música tem sido um meio de comunicação e interação entre a mãe e o feto desde o útero materno, estando muito perto do bebê. São pequenos. Os bebês conhecem e aprendem muitas canções, como canções de ninar nos braços da mãe, canções 
reconfortantes para momentos de ansiedade e festas de aniversário. Quando vou para a escola, levo para a TV as músicas que aprendi com meus pais, etc.

De acordo com o Referencial Curricular para a Educação Infantil: A música está presente em diversas situações da vida. [...] presente na vida diária dos povos, ainda hoje é tocada e dançada por todos seguindo costumes que respeitam as festividades e os momentos próprios a cada manifestação musical. Nestes contextos, as crianças entram em contato com a cultura musical desde cedo e assim começam a aprender suas tradições musicais (RCNEI, 1998).

Desse modo, a música se torna uma atividade muito social, ela abre as portas para o bem-estar pessoal, é uma linguagem importante como qualquer outra área do conhecimento e, portanto, a base do processo educacional-aprendizagem. Assim que seu filho entrar no jardim de infância, ele será confrontado com o mundo da música. Este espaço escolar é marcado por canções que apoiam as rotinas de celebração, rotinas escolares e ensaios e se repete com as habituais necessidades do dia a dia. Fazemos regularmente por nós, na vida escolar e na prática dos professores e seus alunos, o surgimento da música e suas características, habilidades e linguagem.

Com relação ao uso da música, a lei no 11.769 de 18 de agosto de 2008 passa a ser incluída como requisito obrigatório na matriz curricular em todas as escolas da Educação Infantil, fazendo-se necessário ações que tornem o uso da música de forma significativa para os alunos e não de forma desmerecida e empobrecida.

Segundo Craidy (200I), a música não é uma área que não possa ser ignorada na educação infantil, pois as habilidades musicais têm um forte impacto na identidade, na autoestima e na expressão de uma pessoa, cabendo aos professores fazer bom uso desta ferramenta educacional na sua concepção. O que as crianças podem aprender de uma forma divertida e divertida. Será uma atividade divertida.

O uso da música no jardim de infância é muito importante. As crianças não apenas aprendem brincando, mas também proporcionam um ambiente de aprendizagem mais confortável e estão cada vez mais motivadas a participar das aulas. Assim, apresentar conteúdos por meio da música a crianças de o a 5 anos desenvolve relações afetivas, socialização e qualidades cognitivas, facilitando o aprendizado de todas as áreas do conhecimento. 
De acordo com Palhares (2012) as atividades musicais das crianças, vê-se a música como subparte da cultura considerando-a como uma ferramenta para regular as funções psicológicas inter e intrapessoais, sendo que a experiência musical da criança é obtida através da natureza e das relações com pessoas e o ambiente.

Para Ferreira (200I), a convivência com os diferentes sons e ruídos é muito importante, para a criança, pois, traz novas descobertas e, com elas o conhecimento e a exploração do diferente, do novo. Dessa maneira, conclui-se que a música representa mais que uma forma de expressão e integração com o meio; é um elemento que possibilita desenvolver habilidades, conceitos e hipóteses, contribuindo para a formação integral da criança.

\subsection{O professor e a prática da música na Educação Infantil}

A escola é um espaço onde relações sociais se intensificam, se tornando um lugar de constante aprendizado para todos seus componentes, sendo um deles o professor, que neste espaço interacional e social precisa criar condições para promover em seus alunos o desenvolvimento humano integral, cognitivo e afetivo, ou seja, sendo a grande ponte entre o aprendizado e o aluno.

Segundo o Referencial Curricular para Educação Infantil, o ensino da música emerge como proposta específica a ser administrada por professores pedagogos e é considerado fundamental na Educação Infantil (BRASIL, 1998). Portanto, esses professores podem usar a música como um recurso para desenvolver uma variedade de conhecimentos de desenvolvimento. Essa linguagem pode fazer a diferença no ambiente escolar e estabelecer novos comportamentos.

O mundo infantil está repleto de canções nas atividades diárias para tornar o envolvimento dos alunos mais eficaz. Portanto, trabalhar um conteúdo musical que reflita a alegria e a expressão de alegria que os alunos estão tocando é uma forma mais divertida de trabalhar com qualquer conteúdo em sala de aula. Portanto, a música é vista como uma fonte de apoio para o desenvolvimento de outras áreas do conhecimento.

A música na Educação Infantil não se limita ao aspecto musical, mas também inclui aspectos cognitivos e motores que promovem o desenvolvimento holístico do sujeito. 
Deste ponto de vista, o ensino da música é uma ferramenta educacional de fundamental importância no processo de construção do conhecimento musical, uma forma de tocar e interpretar a música, ignorando as outras possibilidades: experimentar, improvisar e inventar (BRITO, 2003).

Godoi (2009) afirma que o ensino da "música tem relação com a percepção e sensibilidade do professor em perceber como esta pode ajudar em sua sala", portanto, as práticas educacionais, utilizando ou não música, devem ter uma finalidade e uma finalidade claras desde o início e os educadores analisam cuidadosamente para aproveitar ao máximo a música durante o processo de aprendizagem, entendendo-se que é necessário. $O$ que isso significa para os alunos?

É provável que os educadores atraiam a atenção dos alunos apresentando novas canções e hinos e novos materiais para as crianças, e eles provavelmente continuarão a se interessar por esse novo aprendizado. Segundo Ferreira (200I, p. IIo), "cabe ao adulto um dos maiores modelos de imitação da criança, ser criativo e crítico na escolha do que apresentar a ela, garantindo que o trabalho seja interessante para ambos".

O ensino de conteúdos através da música permite que as crianças explorem linguagens sensíveis e seu próprio potencial criativo, permitindo-lhes inventar, criar e recriar o mundo ao seu redor. Será mais fácil, mais criativo e mais feliz.

Nesse contexto, um professor que defende a música e busca a riqueza que ela pode trazer contribuirá para o desenvolvimento da criança na percepção e atenção da criança. Além disso, quando canta para o bebê, ela imita vozes e sons de animais e cria uma variedade de sons explorando os sons corporais, batendo, gesticulando, franzindo a testa e dando tapinhas., etc.

\subsection{A música como recurso pedagógico}

A Educação Infantil é um dos momentos mais movimentados e musicais. Portanto, é uma importante ferramenta educacional para apoiar o desenvolvimento infantil de forma planejada e contextual.

Para combinar música com atividades educacionais no cotidiano escolar, os professores precisam ter uma atitude mais ativa e interativa com seus alunos. Portanto, o 
processo de aprendizagem é quando a missão da escola é estimular a descoberta e a descoberta, quando na escola não há mais tédio e monotonia, quando os professores podem oferecer experiências diferentes aos alunos fora das aulas explicadas e direcionadas. Mais fácil. Promova a aprendizagem. Para Brito (2003, p. 45): [...] o professor deve atuar semprecomo animador, estimulador, provedor de informações e vivências que irão enriquecer e ampliar a experiência e o conhecimento das crianças, não apenas do ponto de vista musical, mas integralmente, o que deve ser o objetivo prioritário de toda proposta pedagógica, especialmente na etapa da Educação Infantil.

Os professores trabalham com os alunos e acompanham a musicalização, dependendo do formato do aplicativo, além de facilitar a cooperação e a comunicação as atividades são realizadas, estimulando movimentos específicos que ajudam a organizar o pensamento. Brito (2003, p. 35) afirma que: [...] as cantigas de ninar, as canções de roda, as parlendas e todo tipo de jogo musical tem grande importância, pois, é por meio das interações que se estabelecem que os bebês desenvolvem um repertorio que lhes permitam comunicarse pelos sons: o momento de troca e comunicação sonoro-musical favorecem o desenvolvimento afetivo e cognitivo, bem como a criação de vínculos fortes tanto com os adultos quanto com a música.

Desta forma, a música dá ao ambiente escolar uma sensação diferente e satisfaz os participantes e professores que têm que estudar, tornando o ambiente mais agradável e fácil de aprender. Um meio de ajustar e combinar música. Os planos escolares individuais realizam um trabalho interdisciplinar de acordo com o conteúdo desenvolvido com os alunos em sala de aula. Ser capaz de explorar criativamente diferentes aspectos da vida cotidiana. Promove a socialização e a aprendizagem das crianças. Para Brito (2003, p. 92), se "torna importante brincar e cantar com as crianças, pois, o vínculo afetivo e prazeroso que se estabelece nos grupos em que se canta é forte e significativo".

A integração da música nas atividades educativas pode ocorrer de várias formas, nomeadamente: (gritar, rir), oferecendo brincadeiras em roda que os alunos explicam os ruídos do seu ambiente (chuva, barulho de carro, choro, riso, de acordo com Brito (2003), cantando juntos, aprendemos a escutar uns aos outros, a escutar uns aos outros e a escutar o 
grupo. Desta forma, também desenvolvemos aspectos da individualidade como atenção, concentração, cooperação e trabalho em equipe.

Para Brito (2003) além de cantar, você deve brincar com sua voz explorando diferentes possibilidades acústicas: imitação de vozes de animais, ruído, vogais, consoantes (para enfatizar a formação dos lábios) grandes movimentos (graves) de alto a alto e viceversa), pequeno desenho melódico, etc. (BRITO, 2003, p. 89).

Também é possível sugerir como as ferramentas são utilizadas nas engrenagens do cotidiano escolar, em que professores e mediadores planejam as aulas pedindo aos alunos que forneçam materiais. Um divertido momento de pesquisa e criação, onde o conteúdo da sala de aula interage com outros conteúdos.

As atividades de construção de equipamentos envolvem o diálogo com outras áreas de trabalho. Reciclagem de material refere-se aos conteúdos relacionados à educação ambiental, a relação entre natureza e sociedade e o eixo existe no Referencial curricular nacional para a Educação Infantil. Da mesma forma, pense na variação dos materiais, na evolução dos instrumentos musicais ao longo do tempo e na existência comum de diferentes possibilidades (cada pessoa, lugar, cada instrumento característico de cada época) trabalhando juntos para o mesmo objetivo de fazer música. Desenvolva nas crianças uma atitude de respeito e consciência da diversidade que reflita o pluralismo cultural existente (BRITO, 2003, p. 7I).

É importante entender que não apenas a música escolhida pelo professor deve ser utilizada, mas também respeitar a formação musical que os alunos trazem do seu dia a dia, por menor que seja. Seus comentários e sugestões. Em outras palavras, ouça o que as crianças têm a dizer. Nesse processo de troca e interação, os alunos aprendem com o professor e o professor aprende com os alunos quando há outras lições a serem aprendidas sobre o mesmo tema ou sobre temas diferentes. Freire (2013, p. 25) assegura que "quem ensina aprende e quem aprende ensina ao aprender".

A Educação Infantil possui muitas canções, bem planejadas e, se adequadas à situação, podem oferecer aos alunos um amplo leque de possibilidades de conhecimento, mas os professores têm a responsabilidade e a ética na escolha das aulas. Qual música usar porque a quantidade de produção é enorme e você tem que saber selecioná-la. Também é importante ouvir o que as crianças têm a dizer sobre suas preferências musicais e escolares. 


\section{CONSIDERAÇÕES FINAIS}

A música é considerada uma forma de expressão humana porque pode expressar sentimentos, emoções, situações cotidianas, alegria, tristeza, etc. As crianças na fase de educação infantil expressam-se por meio de movimentos, sons e ritmos, pois desde pequenas vivenciam a expressão musical em seu ambiente, construindo aprendizagens significativas que as ajudam a amadurecer cognitivamente.

Este artigo tem como objetivo refletir sobre a utilização da música na educação infantil, em especial a sua contribuição como recurso didático, aliada à contribuição da prática pedagógica para a formação integral das crianças, buscar respostas às verdadeiras intenções do uso da música no ambiente escolar, e enfatizar o repensar da importância das atitudes dos professores em relação ao uso da música.

O uso da música em sala de aula abre um amplo leque de possibilidades para as atividades pedagógicas, e torna-se viável se o professor escolher a música de forma prometida e adaptá-la aos planos e conteúdos propostos para a educação infantil. Inserir estratégias musicais nas ações pedagógicas é tornar a educação menos tradicional e tornarse uma educação estimulante e fascinante, para que os alunos se tornem ativos e envolvidos, vivenciem situações e atividades interativas e dialógicas, e entendam que cada aluno tem seu próprio processo de construção do conhecimento. A importância da utilização da música como recurso na prática docente de forma planejada e contextual, por meio da utilização de novas possibilidades e novos métodos de ensino, auxilia, apoia o papel do professor em sala de aula.

Ao final deste trabalho, pode-se concluir que o uso da música em sala de aula auxilia no desenvolvimento cognitivo, emocional e motor das crianças. Além de propiciar a cooperação, estimula a participação e a socialização das crianças, torna mais efetiva a construção da aprendizagem e traz alegria na participação nas atividades de ensino.

Porém, é importante ressaltar que quando utilizado de forma interessante, criativa, contextual e significativa, torna-se uma ferramenta indispensável. Por fim, cabe destacar que este trabalho representa uma oportunidade de crescimento intelectual, proporciona um 
aprofundamento de conhecimentos e estuda música na educação infantil de forma crítica e reflexiva.

\section{REFERÊNCIAS BIBLIOGRÁFICAS}

ANDRADE, Annielly da Silva. A música como meio facilitador da aprendizagem na educação. Trabalho de Conclusão de curso. Guarabira: UEPB, 2012.

FERREIRA, Aurélio Buarque de Holanda. Mini Aurélio: o dicionário da língua portuguesa. 8. Ed. Curitiba: Positivo, 2010.

BASSEDAS, Eulália. Aprender e ensinar na educação infantil/ Eulália Bassedas, Teresa. Porto Alegre: Artes Médicas Sul, 1999.

BRASIL. Revisão das diretrizes Curriculares Nacionais da Educação Básica. Brasília: MEC, 2003.

BRASIL, Lei de diretrizes e bases de educação nacional: Lei no 9.394, de 20 de dezembro de 1996.

BRASIL. Ministério de Educação e Cultura. Lei 9394/96: Lei de Diretrizes e Bases da Educação Nacional. Brasília: 1996.

BRASIL, Ministério da Educação e do Desporto, Secretaria de Educação Fundamental. Parâmetros curriculares nacionais. Brasília: MEC/SEF, 1998.

BRASIL. Educação, Ministério e do Desporto, Secretaria de Educação Fundamental; Referencial Curricular Nacional para a Educação Infantil. Brasília: MEC/SEF, 1998. v. ı e 3.

BRASIL Ministério da Educação. Secretaria de Educação Básica. Diretrizes Curriculares para a Educação Infantil. - Brasília: MEC, SEB, 20 o.

BRASIL. Estatuto da criança e do Adolescente. Lei 8.069/90, de I3 de julho de 1990.

BRITO, Teca de Alencar. Música na educação infantil - propostas para a formação integral da criança. São Paulo: Editora Petrópolis, 2003.

CRAIDY, C.M., Kaercher, Silva G.E.P. Educação Infantil, para que te quero? Porto Alegre, 2001. 
FERREIRA, Maria Clotilde Rossetti. Os fazeres na Educação Infantil. 3o. Ed. - São Paulo: Cortez, 20oI.

GODOI, Luis Rodrigo. A importância da música na Educação Infantil. Trabalho de Conclusão de curso. Londrina, UEL, 2009.

LIBÂNEO, José Carlos. Didática. São Paulo. Cortez, ı994.

PAIGE, Alice Smith. O desenvolvimento da pratica reflexiva na educação infantil. Porto Alegre: Artmed, 2010.

PALHARES, Annielly da Silva. A música como meio facilitador da aprendizagem na educação. Trabalho de Conclusão de curso. Guarabira: UEPB, 2012. 